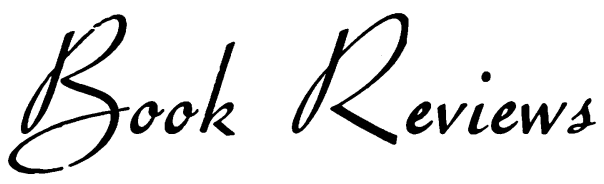

\section{A PRIMER OF PAEDIATRICS}

By E. Hinden, M.D., M.R.C.P. Pp. 356. London: Macdonald \& Co. Ltd. 1957. 25 s.

This book designed for senior medical students and general practitioners is written in an easy conversational style. Dr. Hinden has managed to present contemporary paediatrics in perspective. The child is followed from conception to puberty as a normal human being subjected to changing stresses and the author is concerned particularly with present day stresses. Each section and subsection is developed logically so that the reader is not conscious of the effort of learning. The Primer is not a handbook or a reference book. Unless the reader appreciates this, the lack of an index may cause irritation, but if the book is used as the author intended an index is not necessary. The contents are accurate and up-to-date. Occasionally, when the author touches on controversial subjects, he expresses his own opinions, but not dogmatically. The book can be recommended not only to medical students and family doctors but to paediatricians as an enjoyable form of revision. By making the subject easy, Dr. Hinden has contributed to the welfare of children. It is hoped that future editions will keep pace with the changing scene.

\section{BIOCHEMICAL DISORDERS IN HUMAN DISEASE}

Edited by R. M. S. Thompson, M.A., D.M., and E. J. KING, Ph.D., D.Sc., F.R.I.C. Pp. xiv + 843, with 121 illustrations. London: J. \& A. Churchill Ltd. 1957.

There has been an enormous advance in biochemical knowledge applied to clinical problems in the last few decades. The subject hardly allows itself to be encompassed in one book. The present volume consists of a series of essays dealing with specialized aspects of clinical biochemistry. The authors are all internationally known figures but the Editors have been at some pains to give the whole volume a uniformity and cohesion which is often lacking in volumes which involve multiple authorship. The nature of the subject precludes an exhaustive treatment, but most of the common metabolic disorders are discussed clearly and authoritatively. The book can confidently be recommended as an outline of clinical biochemistry both for students and for postgraduates.

\section{WHITLA'S DICTIONARY OF MEDICAL TREATMENT}

By R. S. Allison, V.R.D., M.D., F.R.C.P., D.P.M. and T. H. Crozier, M.D., B.Sc., F.R.C.P. Ninth edition. Pp. xiii +852 . London: Baillière, Tindall and Cox. 1957. 52s. $6 \mathrm{~d}$.

It would seem clear that any book that has gone through nine editions in a period of 66 years must meet a definite need and it may be asked whether a reviewer can usefully say anything in criticism of such a book. This ninth edition, however, is really an entirely new volume; not only has it been rewritten, but surgical topics have been omitted. The book is thus now confined to medical therapeutics. It has been written exclusively by members of the Belfast School of Medicine and of neighbouring institutions.

In looking at this as a new textbook of therapeutics, the first thing that strikes the reader is that it combines therapeutics with extensive considerations of pathogenesis. This, although valuable in some ways, has led to the production of a very large book, and it has also led to a reduction in the space available for consideration of therapeutics alone. Thus, there is a large section on thrombocytopenic states in which an extensive review is given of modern views on pathogenesis, whereas the entire article on Addison's Disease occupies only two pages, and does not seem to the reviewer adequate to meet the needs of those not accustomed to dealing with these difficult cases. Compression of the section on the pathogenesis of thrombopenia would have permitted an extension of the latter to more useful proportions. Furthermore, Professor Bull's excellent summary of water and electrolyte requirements would have benefited considerably by being allowed more space. It is doubtful whether the section of 15 pages on the psychoneuroses would really help those without a fairly extensive knowledge of the subject.

In general, however, the Editors have maintained a reasonable balance, and it may be said without any equivocation that the information provided is reliable and up to date, and the book can be recommended to senior students and general practitioners who want a readily available compendium of modern procedures in therapeutics. The alphabetical arrangement of diseases in this book undoubtedly makes it very handy for quick reference. 